\title{
Building supply chain resilience in the era of COVID-19: An AHP-DEMATEL approach
}

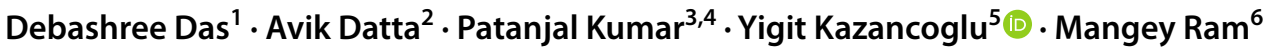

Received: 31 January 2021 / Revised: 28 May 2021 / Accepted: 21 June 2021 / Published online: 6 July 2021

(c) The Author(s), under exclusive licence to Springer Science+Business Media, LLC, part of Springer Nature 2021

\begin{abstract}
COVID-19 pandemic is the worst humanitarian crisis that economies across the globe have witnessed. Forced lockdowns, social distancing, and restricted mobility have contributed to large scale disruptions in the supply chain network. The purpose of the paper is to identify critical factors affecting global supply chain and evaluate strategies for risk reduction in the supply chain network by making it resilient.

Our study incorporates multi-criteria decision approach using Analytic Hierarchy Process (AHP) and Decision-Making Trial and Evaluation Laboratory (DEMATEL) to analyze factors that affected the supply chain networks with the onset of COVID-19. The AHP method enabled to hierarchically rank the factors based on the relative weightage while DEMATEL ascertained the inter-relationships among the factors and classified them into cause and effect groups. The findings of our study identified the cost-optimization as the most significant factor and the human resource management as the least important factor in reducing vulnerabilities of the supply chain network. Our analysis from DEMATEL approach indicate that government support is a significant causal factor which can effectively eliminate the issues plaguing supply chains during this pandemic. The results from our study aim to help policymakers in developing a risk resilient framework that can enhance performance and operational capability of the supply chain, thereby ensuring sustainability and socio-economic well-being of all the stakeholders involved in the entire network.
\end{abstract}

Keywords Analytic Hierarchy Process · COVID-19 $\cdot$ Decision-Making Trial and Evaluation Laboratory · Supply Chain Resilience

Yigit Kazancoglu

yigit.kazancoglu@yasar.edu.tr

Debashree Das

debashree763@gmail.com

Avik Datta

dattabonny@gmail.com

Patanjal Kumar

patanjaliitiim@gmail.com

Mangey Ram

mangeyram@gmail.com

1 Faculty of Management Studies, University of Delhi, New Delhi, Delhi, India

2 Bureau of Indian Standards, New Delhi, India

3 Indian Institute of Management Rohtak, Rohtak, Haryana, India

4 GLA University Mathura, Mathura, India

5 Logistics Management Department, Yasar University, Izmir, Turkey

6 Graphic Era University, Dehradun, India

\section{Introduction}

The world economy was already facing headwinds of trade wars and geo-political conflicts, and the inception of COVID-19 further exacerbated the economic downturn. In no time, COVID-19 spread across continents forcing World Health Organisation to declare it a global health emergency. Even though such events occur less frequently but they have considerable impact on supply chains (Hosseini et al. 2019). As the virus spread, countries began taking multiple measures leading to disruption in trade which became a major tipping point for the global economy as countries began to fall into recessionary trap (Das et al. 2020). The health crisis initially led to disruptions in supply chains within China but with time the effects of the pandemic cascaded through global supply chain network. Samson (2020) reported that the COVID-19 outbreak has led to reduced reliance on international supply chain which has collapsed the entire network. Different components of the supply chain have been 
affected simultaneously leading to complete paralysis of the network (Ivanov and Das 2020) which has tested the loopholes in the global supply chain. (Ivanov 2020).

In the era of COVID-19 pandemic, supply chain resilience and responsiveness are important to cope with sudden variations (Barbieri et al. 2020). Ponomarov and Holcomb (2009) defines supply chain resilience as "the adaptive capability of the supply chain to prepare for unexpected events, respond to disruptions, and recover from them by maintain continuity of operations at the desired level of connectedness and control over structure and function". Ivanov (2020) further elaborated that a viable supply chain comprises of three dimensions-agility, resilience, and sustainability. They established the relationship between resilience and viability. The supply chain vulnerabilities have increased due to frequent disruptions caused by COVID-19 pandemic (Karwasra et al. 2021). It has affected both the supply chain performance and revenue generation capabilities. COVID-19 pandemic has caused demand and supply shocks and most companies have failed to come up with a plan for improving their resilience and recovery process (Remko 2020). It has impacted $94 \%$ of the Fortune 1000 companies (Sherman 2020) and the existent supply chain resilience mechanisms have failed to pull them through the pandemic times. A survey with over 650 respondents conducted by Institute of Supply Management indicated that $97 \%$ of the respondents will be or have been impacted by the pandemic with majority of companies bracing for a severe impact in the latter half of 2020 and early 2021 (Institute for Supply Management 2020). In another survey conducted by IBM spanning more than 3000 executives from 22 industries in 20 countries the executives admitted to the need for better initiatives with regard to use of technology in supply chain (Straight 2020). Infosys Consulting, in a survey found that $19 \%$ of the respondents felt their organizations did not have a contingency plan in place while only $11 \%$ felt their emergency plans were in place for any sort of disruptions (Infosys 2020). ELGi, a global compressor manufacturer, faced major hurdles in managing its raw material inventory due to lack of diversity in its supplier base (Varadaraj 2020). Tech giant Apple having most of its manufacturing units in China faced subdued output for several months due to lack of integration among supply chain agents. Ineffective management of human resource forced Amazon to close some of its warehouses in USA leading to supply chain disruptions (Montgomery 2020). Most companies in the pre-pandemic times relied on company datasets instead of end-to-end supply chain data for demand and supply forecasting, a case typical of meagre use of IT and automated systems in supply chain management (Selko 2021). Thus, when the pandemic unfolded, companies were unable to predict demand and supply constraints which led to supply chain disruption. With COVID-19 sweeping across the globe, companies are facing orthodox demand and supply shocks and while most of the companies have made their supply chains smarter and swifter over time but companies still lack ideas to de-risk their supply chains against pandemic like disruptions. This indicates that there exists a gap in supply chain resilience strategy in literature and their implementation in industry.

In such a scenario, there is a dire need for companies across the world to improve resiliency of their global supply chains (Linton and Vakil 2020) to deal with future shocks. There are numerous studies on supply chain risk management, and continues to be studied from various viewpoints (Sawik 2013a, 2013b; Margolis et al. 2018). The current event of the pandemic has shown that there is need for more work on supply chain resilience based on real life events (Remko 2020) which takes all the parameters in a coherent manner. The COVID-19 induced supply chain disruptions on supply chain resilience and robustness can be mitigated through efficient supply chain risk management (El Baz et al. 2021). Golan et al. (2020) presented a review of the literature on new trends and applications of resilience analytics in supply chain modelling and observed on increasing trends of supply chain resilience literature. Chowdhury et al. (2020) explore the impact of COVID-19 pandemic in the food and beverage industry, they highlighted two types of impacts such as short-term (product expiry, shortage of working capital, and so-forth) and medium-to-long term (reduction in ROI, job cuts, and so-forth) impacts. Mahmoudi et al. (2021) has developed gresilient supply chain management framework to manage and control the disruption caused due to COVID-19 pandemic; the gresilient supply chain refers to the integration of green and resilience aspects of supply chain. Wen and Liao (2021) proposed the algorithm to enhance supply chain resilience under COVID-19 outbreak. Yadav et al. (2020) proposed the internet of things (IoT) based framework to improve the performance of Agri-based supply chain in the COVID-19 pandemic condition. In our paper we have tried to take into consideration the changing dynamics of the world trade and the volatility witnessed with the coronavirus outbreak which has raised issues relating to the vulnerabilities of inter-connected supply chains, and the need to develop a contingency plan and policy framework to ensure resilience of the supply chain. The study involves a comprehensive evaluation of strategic interventions that can help build a resilient supply chain.

Through this study, the following research objectives are evaluated:

1. To identify critical barriers with the inception of COVID-19 on supply chain network;

2. To prioritize and identify causal-effect groups of the identified barriers;

3. To identify various implications and strategies that can aid policymakers in building a resilient supply chain 
In our study we have used a multi-criteria decisionmaking approach using Decision Making Trial and Evaluation Laboratory (DEMATEL)-Analytic Hierarchy Process (AHP) methodology. Through our study we have aimed to develop a robust framework that includes resilient risk management strategic factors that could improve operation capability and performance of the supply chain to protect against future disruptions. The AHP method enabled us to rank the different strategies identified through extensive literature review and focus group discussions with the policy experts; and DEMATEL method helped us to prioritize and evaluate the cause-effect relationship between these factors.

The next Sect. 2 highlights the current work done by the researchers to identify the research gap and investigate the factors that intensify the impact of COVID-19 on the supply chain, followed by Sect. 3 that elaborates the proposed model and the methodology that is undertaken for the multi criteria study through DEMATEL-AHP analysis. The results and discussions are illustrated in Sect. 4, the conclusion from the study are summarized in Sect. 5 .

\section{Literature review}

\subsection{Supply chain resilience}

Study in the sphere of supply chain resilience has been done by researchers over the years and can be traced back to 2000s. Existing literature in supply chain resilience presents elements like contingency plans (Seville et al. 2015), coordination and financial support (Fiksel et al. 2015), human resource management (Blackhurst et al. 2005), use of information technology (Pereira et al. 2014), trust and satisfaction (Day 2014) are precursors for making supply chain resilient. For businesses, managing the supply chain has become most crucial to overcome the current pandemic. The strategic evaluation of the supply chain may help to mitigate the risk of the unforeseeable events, and help the supply chain agents and policymakers to devise a collaborative plan to become resilient (Johnson et al. 2013; Vanpoucke and Ellis, 2019). Despite, the Severe Acute Respiratory Syndrome (SARS) outbreak of 2003 and other health emergencies in the past, companies are still not able to mitigate these risks and this occurs majorly due to company's failure to formulate a long term strategy for building up a resilient supply chain.

\subsection{Proposed strategies}

For developing supply chain resilience, a comprehensive set of strategies are enumerated in this section.

\subsubsection{Process automation and artificial intelligence}

Digital technologies are playing important role in supply chain resilience through high connectivity, accuracy and transparency. Supply chain resilience (SCRes) refers to the supply chain's ability to prevent and absorb changes, and regain the initial performance level after an unexpected disturbance (Belhadi et al. 2021). In recent years, with increased computational power and rapid development of advanced analytics, big data organizations are moving towards process automation and adapting artificial intelligence in their supply chain operations. Their usage helps to trigger alarm immediately in unavoidable and unpredictable events due to its ability to-1) carefully assess the situation and timely actions that helps to mitigate the risk and increase profits; 2 ) ability to deal with asymmetric information and capability to deal with an uncertain environment which cannot be anticipated wholly, with the help of learning and adoption (Legg \& Hutter 2007). This strategic intervention can help the organization, not only by increasing their predictive competencies but also warn the supply chain members to build more resilient supply chain network and to take well-timed decisions (Gulledge and Chavusholu 2008; Baryannis et al. 2019).

\subsubsection{Inventory management}

Inventory is a mandatory buffer required by firms to deal with unanticipated demand or bullwhips. It is always in opposition with the increasing burden of the holding cost. Thus, an efficient inventory management is required to help organizations improve their capability to take judicious decisions on the inventory stocks and availability of product variants to meet the demand during contingencies. Inventory management strategy during crisis enables the organization to adequately manage the inventories of multiple products, reduce the risk of pilling of the inventory, optimize the holding cost and achieve supply chain resilience (Kristianto et al. 2012; Rajesh 2017).

\subsubsection{Outsourcing of business operations}

The offshoring and outsourcing strategy is a strategic choice to focus on the highest value adding activities and the brand valorization (Boffelli et al. 2021). Outsourcing strategies has been adopted by companies across the globe (especially in the case of very innovative processes). Firms outsource their business operations in order to safeguard from over-production cost and cycle times (Talluri and Narasimhan 2004). Outsourcing strategy help firms to consider economies of scale, optimization of cost of production and increase profit margins (Mani et al. 2010). Thus, outsourcing strategy can be adopted by organizations for crisis management and help supply chain 
agents to derive competitive advantage during emergencies (Kroes and Ghosh 2010).

\subsubsection{Geographical integration of supply chain agents}

Ivanov and Dolgui (2020) proposed intertwined supply network in which large scale resilience of individual supply chains are required. The holistic management of the supplychain network requires integration of suppliers, retailers, manufacturers, wholesalers, customers and other stakeholders. Petersen et al. (2005) indicated that the integration supply chain agents that are spread over a geographical region can eliminate the information asymmetry and trade barriers between the agents through free flow of materials, services, information, and improved collaborative relationships. This geographical integration can help agents to take appropriate decisions at the time of disruptions and build a resilient supply chain (Yu et al. 2013).

\subsubsection{Quality assurance}

Quality assurance enables organizations to create brand image, establish new customer base and venture into new horizons, attain customer loyalty, and establish competitive advantage from their counterparts (Cai et al. 2013). At the time of disruptions like COVID-19, quality assurance mainly emerges from safe delivery and reliability of the logistics (Chowdhury and Quaddus 2015). Hence, in order to build supply chain resilience during health emergency, organizations must understand the attributes that help to ascertain quality assurance to the customer. The green initiatives through launch of eco-friendly products without compromising on quality standards and products quality can also be another endeavour for the organizations to ensure sustainable growth (Jabbour \& de Sousa Jabbour 2016).

\subsubsection{Monitoring unethical pricing practices}

Many authors in the past has discussed about the importance of ethics in operating businesses and this has become a major cause of concern during these tragic times (Carter 2000; Simangunsong et al. 2016). Unethical pricing practices by organizations during the pandemic time can not only erode the trust and morale of the customers, but also lead to a massive fall in customer base with mounting economic losses and irreparable brand image. Unethical pricing practices behaviour may provide benefits for the organization in the short-term but compromises on the working and the image of the supply chain as a whole in the long-run (Keating 2009). Monitoring of unethical pricing practices unnecessarily increases the tangible supply chain costs associated with an extra investment required to inspect the supply chain agents (Carter 2000). Thus, for making supply chain resilient, it is essential for organizations to consciously check on their strategic decisions in order to maintain or increase customer base.

\subsubsection{Service quality and customer satisfaction}

Seth et al. (2006) described the importance of service quality in supply chain. In an era where competition is a buzzword, successful delivery of quality service or products leads to improved customer satisfaction and helps in maintaining a competitive advantage that is sustainable (Politis et al. 2014). Building of a resilient supply chain requires an in-depth knowledge of the factors that improvises service quality and ensures customer retention through delivery of satisfactory product or services.

\subsubsection{Human resource management}

Effective human resource management and inculcating a culture of mutual-cooperation and coordination is one of the pillars for building a robust supply chain network (LengnickHall et al. 2013) through emphasis on co-development and co-production of product or services (Ragatz et al. 2002), sharing of information among supply chain partners (Lee et al. 2000). Effective human resource management across the supply chain, has a potential to contribute in improving supply chain adaptability and building resilience against adverse calamities and guarantees a sustained competitive advantage in the market.

\subsubsection{Government support}

Government assistance plays significant role in developing supply chain resilience to face catastrophic events. Implementation and declaration of business-friendly policies taking into consideration organizations of all type, sizes and ownerships at the time of disruption events can stimulate the industrial growth and stabilize the economy (Dube et al. 2016). The provision of financial support to organizations also encourages them to recover from economic crisis and revive their supply chain production.

\subsubsection{Cost optimization}

Cost optimization is one of the most fundamental aspects of supply chain management that is requisite for establishing cost-minimizing of distribution networks and logistical routes. Cost optimization can in turn improve the satisfaction levels of customers through successful delivery of tangible and intangible products at affordable prices (Kelle and Akbulut 2005). Thus, in building a resilience supply chain, cost optimization is significant for its role to improve service level to customers. Cost optimization in supply chain 
includes optimizing purchasing, holding and transportation cost (Farahani and Elahipanah 2008).

\subsubsection{Contingency planning}

Contingency planning involves a sequential and pre-planned process that is designed for precaution against any disrupting events or calamities that are not under the control of an organization (Goran 2004). It helps the organization to reduce the corporate vulnerabilities in supply chains and help mitigate the risk of economic losses. Therefore, understanding the importance of contingency planning during disruptions is crucial for developing supply chain resilience in the network (Guide et al. 2003; Skipper et al. 2009).

\subsection{Theme identification}

Identification of critical factors which are essential to overcome supply chain disruptions have been done through extensive literature review and expert opinions. For our

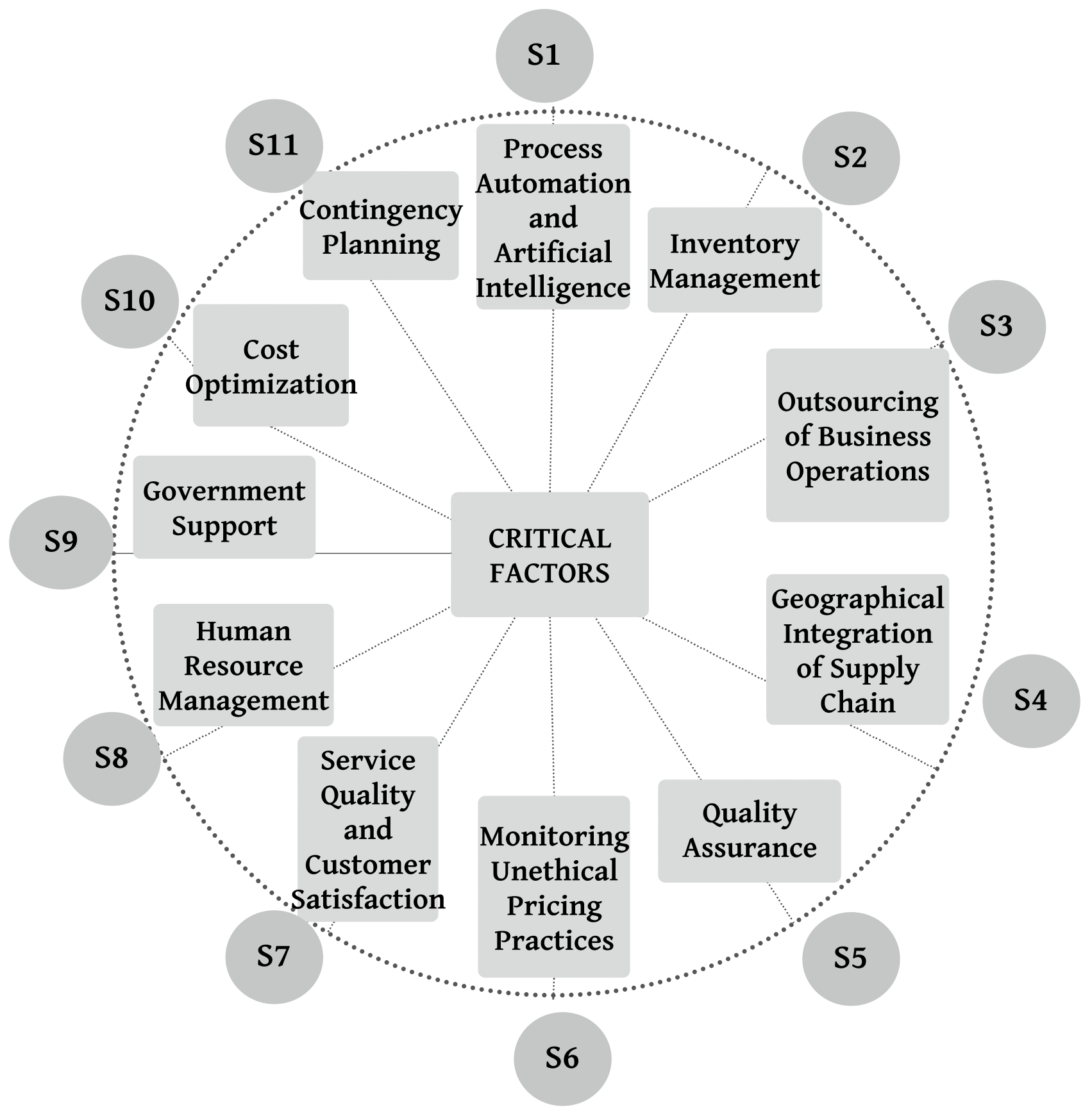

Fig. 1 Critical Factors for Resilient Supply Chain to combat COVID-19 


\section{Phase I: Theme Identification}

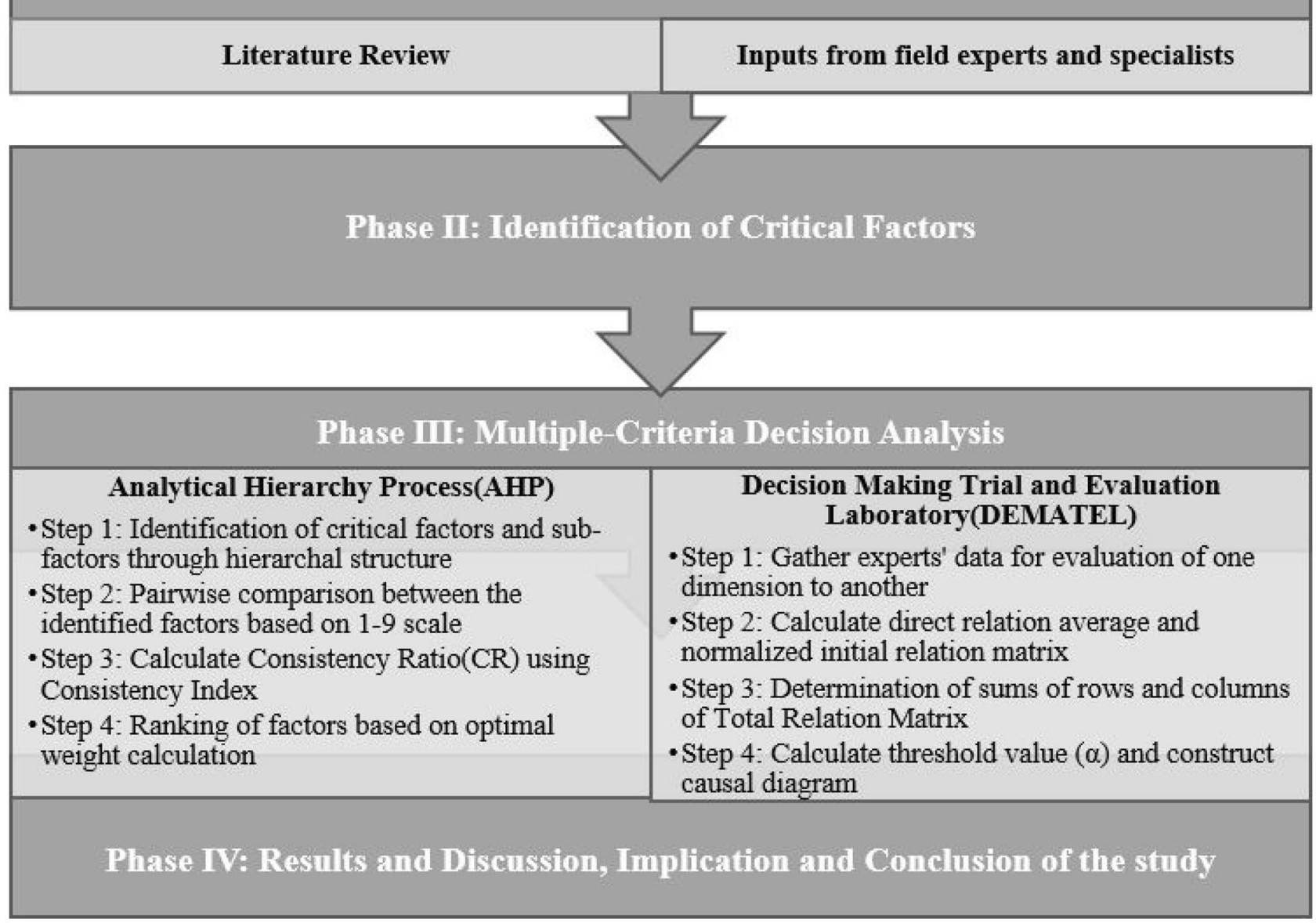

Fig. 2 Research Methodology

study, experts were chosen from various fields which included researchers, academicians, production managers, supply chain strategists, IT analysts and policymakers. Through literature review and expert opinion 11 factors were identified (Fig. 1).

\section{Research Methodology}

The overall framework of our research study has been illustrated in Fig. 2. In the initial stage, group discussions with industry experts were carried out along with extensive literature review. Further interactions were held telephonically with academicians and policymakers, these interactions helped us in preparing a detailed questionnaire which was later used for seeking responses from the expert group. Based on the literature review and opinion of experts, factors were identified which would be useful in overcoming disruptions in the supply chain by making it resilient. Finally, Multi Criteria Decision Making methods of AHP- DEMATEL analysis has been used for grading the factors based on their weightage and splitting them into cause and effect groups.

\subsection{AHP methodology}

Analytic Hierarchy Process (AHP) methodology is a simple mathematical tool that uses the concept of pairwise comparison of factors to solve complex and multi-dimensional problems by generating a hierarchical structure (Albayrak et al. 2004). The concept of AHP was first used to find a solution related to military for planning and resource division (Saaty 1987) and is presently used in numerous domains such as health, engineering, education, industry, and others. In this method the relative importance or weights of tested factors are determined which helps in ranking the factors which helps in making accurate decisions (Cheng and Li 2001). This method uses consistency test which checks out transitivity for filtering out inconsistent responses. The benefits of AHP method over other MCDM methods are its suppleness, intuitive appeal to policymakers and its ability 
to ensure consistent results. Further, the steps of the AHP methodology is enumerated in Appendix 1.

\subsection{Decision making trial and evaluation laboratory (DEMATEL) method}

Decision making trial and evaluation laboratory (DEMATEL) technique was first developed by Battelle Memorial Institute of Geneva Research Centre to visualize the structure of complicated causal relationships through matrixes or digraph. It is a widely used mathematical tool for analysis and solving complex real-world problems (Fontela and Gabus 1972). The solution of complex real world problems requires a number of strategies to be implemented in unison rather than taking a single strategy in isolation. Thus, it becomes critically important to determine the importance of each strategy and evaluate the direct and indirect relationship of these strategies on one another. DEMATEL method makes a pair wise comparison between different parameters of a complex system to evaluate the causal interrelations and the degree of influence between the parameters. A visual representation of the causal relationships is done by means of a structural matrix or diagraph, which segregates the parameters into cause and effect groups. The diagraph gives an idea of the most influential parameter which has the maximum impact potential which facilitates us in the decision-making process. The steps involved in DEMATEL method is elaborated in Appendix 2.

\section{Case example}

This section evaluates and presents the case discussion of a multi-national organisation engaged in retail manufacturing. The case study has been used for identification and analysis of identified risk-resilient strategies using multi-criteria decision-making models.

\subsection{Background of the subject company}

The company that we have chosen as a part of our case study is one of the leading consumer goods companies having its footprints in around 190 countries with significant presence in Asia, Europe and the Americas. The company's product category ranges from baby foods to soaps to pharmaceutical products and they are covered under more than 300 brands. The company considers its vast supply chain network as the backbone of the organisation which involves sourcing raw materials from suppliers and delivering end products to its customers. It procures raw materials from over 1000 suppliers across the globe and more than 90,000 non suppliers. The company's supply chain network is quite diverse engaging a network of 50,000 employees besides a million farmers and transports a distance of more than 1 billion kilometres a year with an estimated expenditure of more than 30 billion euros. Over the years the company has undertaken multiple initiatives for streamlining the supply chain network by implementing new purchase models, pruning the human resource and digitizing work processes.

With the inception of COVID-19, almost all industries have been exposed to major problems with respect to managing their logistics and supply chains and the case company is no exception. The uncontrollable spread of virus forced governments to order shutdowns leading to demand and supply shocks which affected the case company to a considerable extent as reflected overall sales growth reported at $0 \%$ in the first quarter of 2020. The lockdowns impacted consumer demand patterns along with unforeseen volatility in the market leading to massive inventory shortages, warehouse discrepancies and critical issues in supply chain management of the company under study. The pandemic has disturbed the transparency across the multitier supply chains creating widespread fear and distrust among all the stakeholders involved in the channel. Doubts with respect to determining the origin of supply materials, safety measures undertaken on the work floor and identifying alternative sources for extracting raw materials have now become critical components to bridge the gap and keep production running and enable safe delivery to customers. The pandemic has brought into focus the necessity for interventions which will be able to predict consumer behaviour and respond appropriately, ensure safety of employees and customers, identify logistical bottlenecks, identify and chalk out a contingency plan so that the supply chain network emerge swifter, leaner and smarter.

In the current landscape, the company has targeted shortterm response measures to stimulate sales by providing endto-end safety measures, building consumer's trust and investment in promotional ventures. The company anticipates that besides these short-term strategic interventions to tackle the pandemic issue, several other quick action long term interventions are required across the end-to-end supply chain to ensure sustainable improvement in business operations. Despite best efforts by companies across the globe to streamline supply chain operations, COVID-19 has posed a unique hurdle which they have failed to cross (Remko 2020). Therefore, the current study can provide help to the industry which is working day in and out to get their supply chains back to the pre-pandemic levels besides making it resilient for the future.

\subsection{Validation of factors}

Through our literature review, the strategic factors that influenced the supply-chain operations with the outbreak of COVID-19 pandemic were identified. However, the practical implications of these strategies may be different across organisations. To enhance the validity of the data, we interviewed and conducted a survey with the experts to improve the internal validity of the set criteria shortlisted and also 
check the external validity or practical applicability of the identified factors. A questionnaire was designed as shown in Appendix 3 for gathering feedback and opinion of experts.

The experts were to rank and prioritize the factors to identify whether a particular strategic intervention can be effective firewall against future disruptions. With respect to the current unanticipated socio-economic shock inflicted by the spread of virus, the experts were asked to critically review from the current perspective and suggest changes in terms of adding or omitting factors identified through exhaustive literature review. Experts strongly believed that these strategies selected have the potential to qualitatively enrich the study and capture critical factors that can enable the organisations to build a resilient supply chain. Experts identified customer satisfaction to have a causal relationship with service quality, therefore, these two factors were mere merged together into one for further analysis. After the questionnaire survey with the experts, an in-depth personal interview further helped us to check the construct validity and practical applicability of all selected eleven strategies, namely, Process Automation and Artificial Intelligence (S1), Inventory Management (S2), Outsourcing of Business Operations (S3), Geographical Integration of Supply Chain Agents (S4), Quality Assurance (S5), Monitoring Unethical Pricing Practices (S6), Service Quality and Customer Satisfaction (S7), Human Resource Management (S8), Government Support (S9), Cost Optimization (S10) and Contingency Planning (S11).

\section{Results}

In this section, the numerical analysis and related results of the identified strategies are presented in the following subsections.

\subsection{AHP analysis}

The AHP method in our study enables us to prioritize the identified the factors that are essential to build a resilient supply chain network that can shield against unanticipated disruptions. Based on the responses received from various experts, critical factors have been ranked in accordance with their normalized weights as shown in Table 1.

The findings of our study indicate that Cost Optimization (S10) is the most significant factor with rank one and weightage of $22 \%$. It plays a vital role in making supply chain resilient through optimization in purchasing, holding, transportation cost, seamless flow of goods and services and better inventory management. It is followed by Contingency Planning (S11) at rank two with a weightage of $15 \%$ which gives importance to developing an in-built mechanism within the organization to deal with external shocks. Though planning for contingencies may appear to be an expensive and not so important task for most companies, it remains an important factor in making the supply chain network work efficiently. Geographical Integration of Supply chain agents (S4) has been found to be the third most important factor which leads to cost optimization besides helping companies in designing their contingency plans. Inventory Management is another important factor (S2) as per our analysis which is closely linked to the top three factors and can provide timely resolution to manage the crisis. Inventory Management also acts as a proxy for measuring how well the supply chain agents are integrated or geographical spread of the supply chain agents.

Other factors like Service Quality and Customer Satisfaction (S7) and Quality Assurance (S5) have lower weightage. One of the possible reasons for lower ranking of these factors is that they are linked to factors like human resource management (S8), and Process Automation and Artificial

Table 1 AHP Ranking

\begin{tabular}{|c|c|c|c|c|c|c|c|c|c|c|c|c|c|}
\hline Critical Factors & S1 & $\mathrm{S} 2$ & S3 & S4 & S5 & S6 & S7 & S8 & S9 & $\mathrm{S} 10$ & S11 & Criteria Weights & Rank \\
\hline $\mathrm{S} 1$ & 1 & 0.33 & 0.33 & 0.33 & 1 & 0.33 & 0.33 & 7 & 0.2 & 0.33 & 0.2 & $4 \%$ & 10 \\
\hline $\mathrm{S} 2$ & 3 & 1 & 3 & 1 & 5 & 5 & 1 & 5 & 3 & 1 & 1 & $12 \%$ & 4 \\
\hline S3 & 3 & 0.33 & 1 & 0.2 & 5 & 3 & 0.33 & 5 & 3 & 0.14 & 0.2 & $6 \%$ & 6 \\
\hline S4 & 3 & 1 & 5 & 1 & 7 & 7 & 5 & 5 & 1 & 0.2 & 1 & $13 \%$ & 3 \\
\hline S5 & 1 & 0.2 & 0.2 & 0.14 & 1 & 0.2 & 0.2 & 9 & 3 & 0.11 & 0.14 & $4 \%$ & 9 \\
\hline S6 & 3 & 0.2 & 0.33 & 0.14 & 5 & 1 & 0.14 & 5 & 3 & 0.11 & 0.2 & $5 \%$ & 8 \\
\hline S7 & 3 & 1 & 3 & 0.2 & 5 & 7 & 1 & 7 & 3 & 0.14 & 0.2 & $10 \%$ & 5 \\
\hline S8 & 0.14 & 0.2 & 0.2 & 0.2 & 0.11 & 0.2 & 0.14 & 1 & 0.33 & 0.33 & 0.33 & $2 \%$ & 11 \\
\hline S9 & 5 & 0.33 & 0.33 & 1 & 0.33 & 0.33 & 0.33 & 3 & 1 & 0.33 & 1 & $6 \%$ & 7 \\
\hline $\mathrm{S} 10$ & 3 & 1 & 7 & 5 & 9 & 9 & 7 & 3 & 3 & 1 & 1 & $22 \%$ & 1 \\
\hline S11 & 5 & 1 & 5 & 1 & 7 & 5 & 5 & 3 & 1 & 1 & 1 & $15 \%$ & 2 \\
\hline
\end{tabular}


Table 2 Direct Relation Matrix (A)

\begin{tabular}{llllllllllll}
\hline Critical Factors & S1 & S2 & S3 & S4 & S5 & S6 & S7 & S8 & S9 & S10 & S11 \\
\hline S1 & 0.00 & 3.90 & 1.90 & 2.20 & 0.80 & 1.90 & 1.80 & 0.80 & 1.10 & 3.10 & 3.30 \\
S2 & 2.10 & 0.00 & 2.80 & 3.10 & 0.00 & 2.10 & 2.80 & 0.50 & 0.30 & 2.80 & 2.20 \\
S3 & 2.10 & 2.90 & 0.00 & 2.80 & 2.20 & 1.70 & 2.30 & 1.10 & 0.20 & 2.90 & 2.10 \\
S4 & 1.80 & 3.20 & 3.10 & 0.00 & 2.10 & 2.80 & 3.10 & 1.90 & 0.20 & 2.90 & 2.20 \\
S5 & 0.10 & 0.60 & 0.80 & 1.20 & 0.00 & 3.90 & 4.10 & 2.10 & 0.30 & 1.80 & 1.30 \\
S6 & 0.10 & 2.10 & 1.90 & 2.20 & 3.10 & 0.00 & 2.70 & 0.00 & 0.20 & 2.30 & 2.10 \\
S7 & 0.30 & 1.90 & 2.10 & 2.30 & 4.10 & 2.10 & 0.00 & 1.80 & 0.20 & 2.10 & 1.20 \\
S8 & 0.10 & 0.80 & 0.60 & 0.70 & 3.20 & 0.40 & 2.10 & 0.00 & 0.20 & 1.30 & 1.70 \\
S9 & 2.10 & 3.20 & 3.00 & 3.20 & 1.10 & 3.10 & 1.90 & 3.10 & 0.00 & 3.20 & 3.80 \\
S10 & 1.20 & 2.90 & 3.30 & 3.10 & 1.10 & 2.90 & 3.10 & 0.00 & 2.10 & 0.00 & 1.90 \\
S11 & 1.90 & 1.80 & 2.30 & 2.10 & 2.10 & 3.10 & 3.00 & 1.10 & 2.90 & 3.10 & 0.00 \\
\hline
\end{tabular}

Intelligence (S1). Organizations try to improve their service quality by reducing delivery times which requires automating processes besides having adequate manpower for delivery of good and services, often these factors are neglected due to possible increase in expenditure leading to a crunch in working capital. This ignorance ultimately makes the supply chain susceptible to disruptions. The lower weightage of the factor Outsourcing of business operations (S3) may lead to deliver delays, increase in expenditure and hence was not found to be a sustainable viable option. Monitoring unethical pricing practices (S6) and Government Support (S9) were found to be ranking low at the bottom. Since inconsistency in intra-ministerial policy during pandemic acts as a roadblock for the industry, so firms tend to take a stance by supporting government hawkishly and prefer to adopt an autonomous flexi price-setting mechanism wherein it is determined by market forces rather than being dictated by the government.

\subsection{DEMATEL analysis}

In our study we have used the DEMATEL method to segregate the factors into cause and effect groups based on their relative significance. Responses were collected from various field experts and recorded in the form of a direct relation matrix (A) as shown in Table 2 after a pair-wise comparison of the factors were made.

The direct relation matrix is then normalized to eliminate data redundancies to get a Normalized direct relation matrix (Z) as shown in Table 3.

The Total Relation Matrix (T) as indicated in Table 4 provides an insight into total pair wise relationships of all identified factors and it considers indirect influences of a factor over others.

The $\mathrm{R}+\mathrm{C}$ variable in Table 5 signify the total influence potential or importance of a factor, and $\mathrm{R}-\mathrm{C}$ values indicate the net influence potential of a factor. Thus, if $\mathrm{R}-\mathrm{C}>0$ it indicates a given factor is a causal factor and it has the potential to influence other factors. On the other hand, if $\mathrm{R}-\mathrm{C}<0$, then the factor belongs to effect group and such factors are influenced by other factors.

Based on our analysis there are three causal factors namely- Process Automation and Artificial Intelligence (S1), Geographical Integration of Supply Chain (S4), and Government Support (S9). It is evident that Government Support (S9) is the most influential factor with the highest $\mathrm{R}-\mathrm{C}$ value. Thus, during crisis, government's intervention through financial and economic support is most essential component for building a resilient supply chain.
Table 3 Normalized Direct Relation Matrix (Z)

\begin{tabular}{llllllllllll}
\hline Critical Factors & S1 & S2 & S3 & S4 & S5 & S6 & S7 & S8 & S9 & S10 & S11 \\
\hline S1 & 0.00 & 0.14 & 0.07 & 0.08 & 0.03 & 0.07 & 0.07 & 0.03 & 0.04 & 0.11 & 0.12 \\
S2 & 0.08 & 0.00 & 0.10 & 0.11 & 0.00 & 0.08 & 0.10 & 0.02 & 0.01 & 0.10 & 0.08 \\
S3 & 0.08 & 0.11 & 0.00 & 0.10 & 0.08 & 0.06 & 0.08 & 0.04 & 0.01 & 0.11 & 0.08 \\
S4 & 0.07 & 0.12 & 0.11 & 0.00 & 0.08 & 0.10 & 0.11 & 0.07 & 0.01 & 0.11 & 0.08 \\
S5 & 0.00 & 0.02 & 0.03 & 0.04 & 0.00 & 0.14 & 0.15 & 0.08 & 0.01 & 0.07 & 0.05 \\
S6 & 0.00 & 0.08 & 0.07 & 0.08 & 0.11 & 0.00 & 0.10 & 0.00 & 0.01 & 0.08 & 0.08 \\
S7 & 0.01 & 0.07 & 0.08 & 0.08 & 0.15 & 0.08 & 0.00 & 0.07 & 0.01 & 0.08 & 0.04 \\
S8 & 0.00 & 0.03 & 0.02 & 0.03 & 0.12 & 0.01 & 0.08 & 0.00 & 0.01 & 0.05 & 0.06 \\
S9 & 0.08 & 0.12 & 0.11 & 0.12 & 0.04 & 0.11 & 0.07 & 0.11 & 0.00 & 0.12 & 0.14 \\
S10 & 0.04 & 0.11 & 0.12 & 0.11 & 0.04 & 0.11 & 0.11 & 0.00 & 0.08 & 0.00 & 0.07 \\
S11 & 0.07 & 0.07 & 0.08 & 0.08 & 0.08 & 0.11 & 0.11 & 0.04 & 0.11 & 0.11 & 0.00 \\
\hline
\end{tabular}


Table 4 Total Relation Matrix (T)

\begin{tabular}{lcccccccccccc}
\hline Critical Factors & S1 & S2 & S3 & S4 & S5 & S6 & S7 & S8 & S9 & S10 & S11 & R \\
\hline S1 & -0.03 & 0.12 & 0.03 & 0.04 & 0.00 & 0.03 & 0.02 & 0.02 & 0.02 & 0.08 & 0.09 & 0.43 \\
S2 & 0.06 & -0.04 & 0.07 & 0.09 & -0.04 & 0.05 & 0.07 & 0.01 & 0.00 & 0.07 & 0.05 & 0.38 \\
S3 & 0.06 & 0.08 & -0.04 & 0.07 & 0.06 & 0.02 & 0.04 & 0.03 & -0.01 & 0.07 & 0.05 & 0.43 \\
S4 & 0.05 & 0.08 & 0.08 & -0.05 & 0.04 & 0.07 & 0.07 & 0.06 & -0.01 & 0.07 & 0.05 & 0.51 \\
S5 & 0.00 & -0.01 & 0.00 & 0.02 & -0.05 & 0.13 & 0.13 & 0.07 & 0.00 & 0.04 & 0.03 & 0.36 \\
S6 & -0.01 & 0.06 & 0.04 & 0.05 & 0.10 & -0.04 & 0.06 & -0.02 & -0.01 & 0.06 & 0.06 & 0.35 \\
S7 & 0.00 & 0.05 & 0.05 & 0.06 & 0.13 & 0.04 & -0.05 & 0.05 & 0.00 & 0.05 & 0.02 & 0.39 \\
S8 & 0.00 & 0.02 & 0.01 & 0.01 & 0.11 & -0.02 & 0.05 & -0.01 & 0.00 & 0.03 & 0.05 & 0.24 \\
S9 & 0.05 & 0.07 & 0.07 & 0.08 & 0.00 & 0.07 & 0.01 & 0.10 & -0.02 & 0.07 & 0.10 & 0.59 \\
S10 & 0.02 & 0.07 & 0.09 & 0.08 & 0.01 & 0.07 & 0.08 & -0.03 & 0.07 & -0.05 & 0.03 & 0.44 \\
S11 & 0.05 & 0.02 & 0.05 & 0.03 & 0.04 & 0.08 & 0.07 & 0.02 & 0.10 & 0.07 & -0.05 & 0.49 \\
C & 0.24 & 0.51 & 0.45 & 0.48 & 0.40 & 0.50 & 0.56 & 0.28 & 0.15 & 0.55 & 0.49 & 4.61 \\
\hline
\end{tabular}

The effect group has remaining eight parametersInventory Management (S2), Outsourcing of Business Operations(S3), Quality Assurance(S5), Monitoring Unethical Pricing Practices (S6), Service Quality and Customer Satisfaction (S7), Human Resource Management (S8), Cost Optimization(S10), and Contingency Planning (S11), these parameters are influenced by causal parameters. Service Quality and Customer Satisfaction (S7) was observed to have the lowest $\mathrm{R}-\mathrm{C}$ value and is highly influenced by other parameters.

The inner dependency matrix is shown in Table 6. In the inner dependency matrix, the insignificant elements were eliminated that were found to have a value lesser than the threshold value $(\alpha=0.038)$.

The causal diagraph represents the nature and direction of relationship between the factors. For instance, the value of the element $t_{35}(0.06)$ which is greater than threshold value (0.038) so it will be symbolized with an arrow directed from Outsourcing of Business Operations (S3) to Quality Assurance (S5) in the diagraph as shown in Fig. 3. The causal diagraph demonstrates other uni-directional and bi-directional relationship between variables.
The pictorial representation of the factors based on the cause and effect group depicting relationship between total influence potential and net influence potential can be seen from Fig. 4 .

\section{Discussion}

From the analysis it is apparent that the Government Support (S9) is the most important factor in the casual group and can play a significant role in removal of bottlenecks thereby leading to better management of inventory, cost optimization, compliance to health protocols, and help companies in making strategic decisions with regard to their emergency preparedness plans. The second most significant factor is Process Automation and Artificial Intelligence (S1), constant innovation and revolutionizing of technological inputs can enrich the functioning of the entire supply chain network and improve productivity (Wu et al. 2016). Innovation has been considered as one of the most significant drivers to counter impact of COVID-19 on supply chain (Thilmany et al. 2021). The data driven decisions based on real time critical data helps in demand forecasting and controlling supply shocks
Table 5 Total and Net Effects of Each Factor

\begin{tabular}{lllllll}
\hline Critical Factors & $\mathrm{R}$ & $\mathrm{C}$ & $\mathrm{R}+\mathrm{C}$ & $\mathrm{R}-\mathrm{C}$ & Cause or Effect & Rank \\
\hline S1 & 0.430 & 0.244 & 0.673 & 0.186 & Cause & 10 \\
S2 & 0.382 & 0.505 & 0.887 & -0.123 & Effect & 5 \\
S3 & 0.430 & 0.449 & 0.879 & -0.019 & Effect & 6 \\
S4 & 0.510 & 0.479 & 0.988 & 0.031 & Cause & 2 \\
S5 & 0.358 & 0.400 & 0.757 & -0.042 & Effect & 8 \\
S6 & 0.346 & 0.504 & 0.850 & -0.158 & Effect & 7 \\
S7 & 0.394 & 0.559 & 0.954 & -0.165 & Effect & 4 \\
S8 & 0.235 & 0.278 & 0.513 & -0.043 & Effect & 11 \\
S9 & 0.594 & 0.149 & 0.743 & 0.445 & Cause & 9 \\
S10 & 0.440 & 0.550 & 0.990 & -0.110 & Effect & 1 \\
S11 & 0.487 & 0.489 & 0.976 & -0.003 & Effect & 3 \\
\hline
\end{tabular}


Table 6 Inner Dependency Matrix

\begin{tabular}{lccccccccccc}
\hline Critical Factors & S1 & S2 & S3 & S4 & S5 & S6 & S7 & S8 & S9 & S10 & S11 \\
\hline S1 & - & 0.12 & - & 0.04 & - & - & - & - & - & 0.08 & 0.09 \\
S2 & 0.06 & - & 0.07 & 0.08 & - & 0.05 & 0.07 & - & - & 0.07 & 0.05 \\
S3 & 0.06 & 0.08 & - & 0.07 & 0.06 & - & 0.04 & - & - & 0.07 & 0.05 \\
S4 & 0.05 & 0.08 & 0.08 & - & 0.04 & 0.07 & 0.07 & 0.06 & - & 0.07 & 0.05 \\
S5 & - & - & - & - & - & 0.13 & 0.13 & 0.07 & - & 0.04 & - \\
S6 & - & 0.06 & 0.04 & 0.05 & 0.10 & - & 0.06 & & - & 0.06 & 0.06 \\
S7 & - & 0.05 & 0.05 & 0.06 & 0.13 & 0.04 & - & 0.05 & - & 0.05 & \\
S8 & - & - & - & - & 0.11 & - & 0.05 & - & - & - & 0.05 \\
S9 & 0.05 & 0.07 & 0.07 & 0.07 & - & 0.07 & & 0.10 & - & 0.07 & 0.10 \\
S10 & & 0.07 & 0.09 & 0.08 & - & 0.07 & 0.08 & - & 0.07 & - & - \\
S11 & 0.05 & - & 0.05 & - & 0.04 & 0.07 & 0.07 & - & 0.10 & 0.07 & - \\
\hline
\end{tabular}

(Cachon and Fisher 2000), also use of technology helps in reducing delays and resource optimization (Savitz and Weber 2006) leading to better customer satisfaction. Thus, it is evident that use of technology makes the supply chain network robust and immune to crisis. The lack of geographical and functional integration of supply chain is identified as the last causal factor, which leads to uncertainty in the supply chain network (Rodrigue 2006) that can further get aggravated during crisis. Geographical Integration of Supply Chain (S 4) is therefore one of the critical factors which can bring about resilience in the supply chain network and defines efficiency and profitability of the supply chain system (Hoek 1998).

To build a robust and reliable supply chain network, it is critically important that supply chain agents have a proactive plan to deal with contingencies which is evident from the $\mathrm{R}-\mathrm{C}$ value $(-0.003)$ of the factor Contingency Planning (S11) in the effect group which is nearest to centre. This is the least influential causal factor and can lead

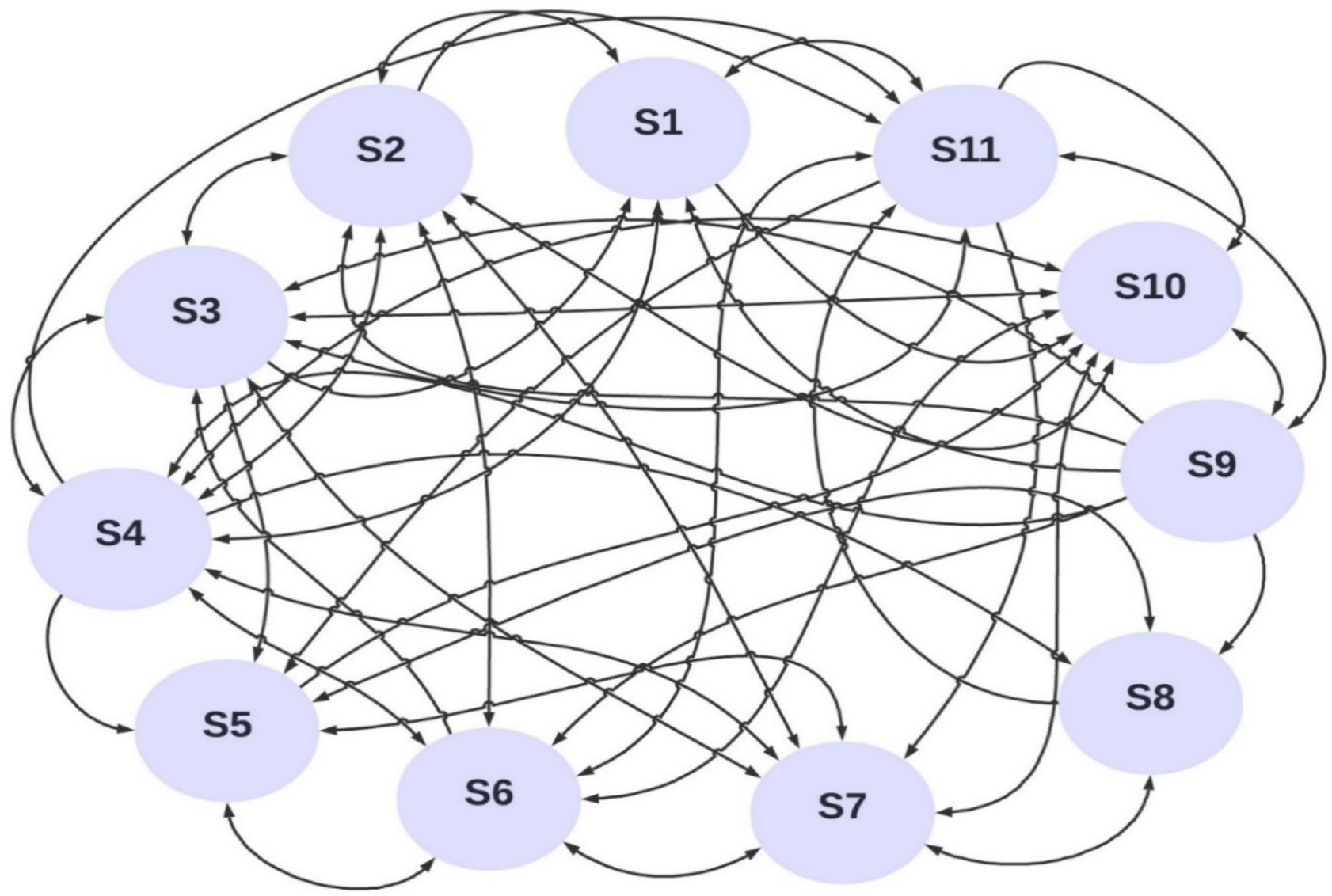

Fig. 3 Diagraph of Critical Factors 
Fig. 4 Diagraph of Critical Factors

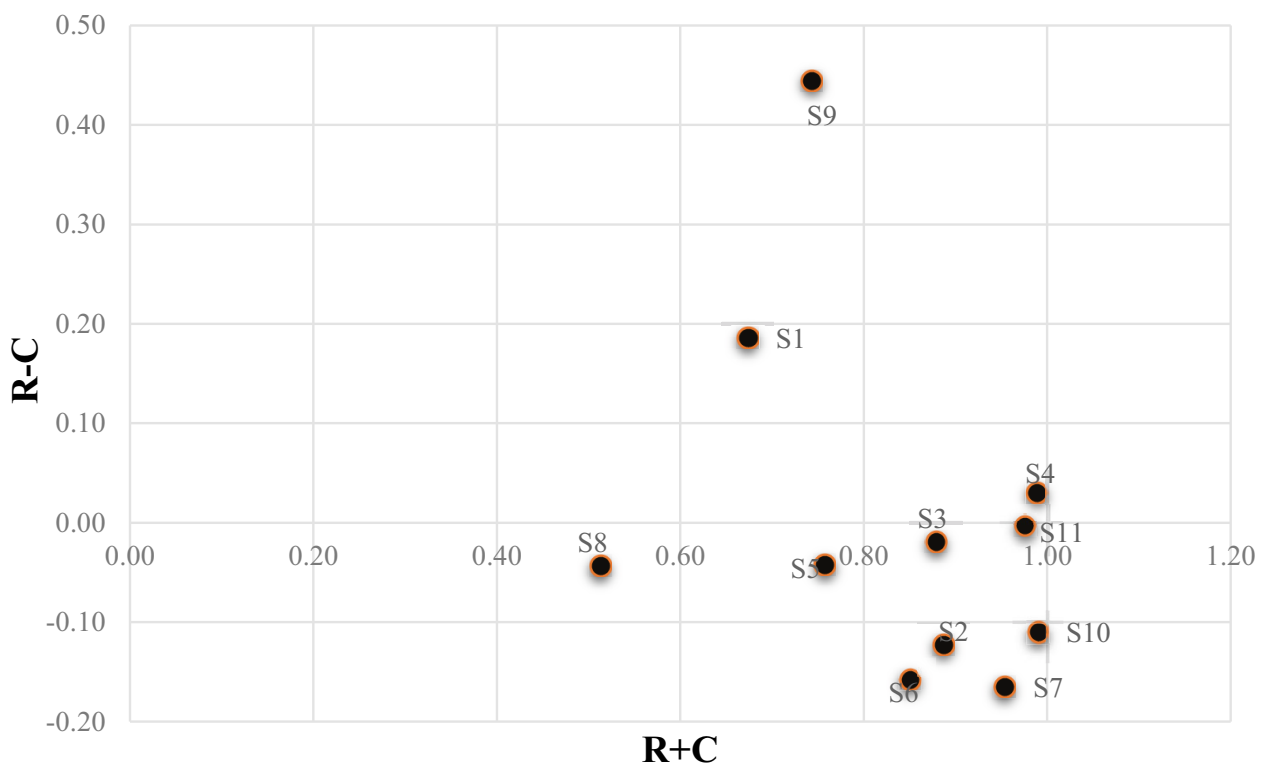

to severe supply chain disruptions at the time of crisis (Hale and Mober 2005). Outsourcing of Business Operations (S3) is the next important factor in our study. An effective tool to make supply chain function efficiently is to outsource certain operations and collaborate with other supply chain agents (Scholten and Schilder 2015). Thus, when supply chain agents work in close association without any information asymmetry then it helps in dealing with disruptions more effectively (Crook et al. 2008).

Another factor identified that helps in establishing a robust supply chain is through Quality Assurance (S5) which helps in minimizing the risk of reverse logistics thereby leading to cost optimization and combat economic disruptions (Zsidisin et al. 2004). The study also supports setting up an efficient human resource management system for greater adaptability and resilience across the supply chain (Soni and Jain 2011). Human resource management (S8) as a significant factor can help in making the supply chain flexible, adaptive, and immune to disruptions. Cost Optimization (S10) by reducing transportation cost, holding cost (Farahani and Elahipanah 2008) is identified as another significant factor that can build a resilient supply chain, further complimenting it with a well-organized inventory management system within the firms can be executed through several optimization tools like IoT, Big Data to ensure that supply chain network is quick enough to respond to demand and supply shocks. The finding of our study corroborates the fact that Inventory Management (S2) is one of the critical factors in building a network where there is seamless flow of goods and services. Monitoring Unethical Pricing Practices (S6) is found to be an important factor which severely affects reputation of firms (Roberts and Dowling 2002). While unethical behaviour may help firms with short-term economic benefit but it severely impacts the reputation and overall functioning of the supply chain (Frazier et al. 1988). Service Quality and Customer Satisfaction (S7) is least important factor as per our findings and can affect the cycle time, reduce profits, increase inventory stocks with direct influence on the firm's performance (Sureshchandar et al. 2002).

\section{Implications}

The current study is relevant for all stakeholders engaged in supply chain management as the entire global supply chain has been severely disrupted by COVID-19. The results from the study aims to help policymakers in designing a resilient framework which can not only absorb external shocks like COVID-19 but also enhance performance and operational capability of the supply chain network. Given the magnitude of losses since the inception of COVID-19, our analysis can motivate businesses to adopt risk resiliency measures by identifying vulnerabilities in the system to protect against future disruptions in the network. Further, the study can be generalized across various sectors to overcome COVID like disruptions by building resilience.

Since the inception of COVID-19 pandemic, research and awareness about supply chain efficiency has exponentially grown as organisations have realised the significance of a timely and sustainable disaster management plan that can build operational resilience and safeguard business functioning in the wake of growing health crisis. Over the course of the pandemic, numerous guidelines and protocols relating to health strategy, technology and policy have been framed to combat socio-economic impact of COVID-19. In this research, through domain 
specific inputs from experts and literature review, the present research has identified the most significant critical factors that are could be used in building a resilient supply chain to enhance logistical as well as operational efficiency. Hence, it is recommended that decision makers should focus upon these aspects to achieve the stated objective of supply chain resilience.

By applying the hybrid approach of incorporating a qualitative inquiry through expert opinion, literature review, and application of MCDM methods to quantitatively analyse the factors, the current work provides precise information about the relative importance of each factor through their respective priority ranks and their cause-effect interrelationship.

Our study suggests policymakers ought to focus on cost optimization for making a robust supply chain. Cost optimization is a proxy for identifying better inventory management which leads to significant reduction in overhead costs. Another factor which needs urgent focus of managers is planning for low frequency-high impact contingencies. Contingencies bring along with them plethora of opportunities. Companies need to cash in on such opportunities by embracing usage of automation and artificial intelligence. It is worth mentioning that usage of automation and artificial intelligence, which is a significant causal factor, leads to better contingency planning, human resource management, and inventory management. The most significant causal factor which if tweaked can bring about wholesome changes in supply chains is government support which can be provided in terms of policies for easing compliance, subsidies, interest moratoriums can go a long way overcoming short term supply chain shocks. For companies having vast supply chain networks, geographical integration of supply chain agents is also crucial as it eliminates logistical bottlenecks, reduces costs and leads to better operational efficiency.

Managerial implications our analysis are enormous as it provides a broad idea to the management as which factors can be prioritized and need to be focussed for achieving supply chain resiliency. Our study also helps managers by way of segregating factors into cause and effect groups, this can further enable them to undertake an in-depth analysis of the inherent weakness within and outside the organisation and help chalk out a plan for implementing growth stimulating strategies that ensures future resilience. A resilient supply chain can augment the capability of supply chain agents to understand and react to the ramifications of unpredictable events like COVID-19, earth quakes, cyclones, to bounce back to its original state or move towards better in terms of operational performance after adverse events (Christopher and Peck 2004). As far as social implications are concerned; our study can go a long way in reducing the susceptibility of the supply chain network thereby ensuring sustainability and socio-economic well-being of all stakeholders involved in the network. Our study can help in planning for the future and to address the challenges faced by numerous vulnerable workers during this pandemic.

\section{Conclusion}

COVID-19 pandemic has broken all linkages of the supply chain systems leading to large scale disruptions worldwide. The combined AHP-DEMATEL methodology provides an insight into the possible ways in which supply chain network can be made resilient. It provides a structured approach in evaluating the importance of each factor and help organizations devise appropriate strategic framework to combat the COVID-19 emergency by building a robust supply chain. By using the AHP model, the critical factors have been prioritized wherein the factor Cost Optimization was identified as the most significant factor, while on the other hand effective human resource management is evaluated as the least important factor. Further, the causal relationships have been evaluated and the critical factors identified were classified into cause and effect groups through the DEMATEL method. The results obtained by the DEMATEL method are in consensus with AHP ranking, the Cost optimization factor has been unanimously recognized as most influential with the highest intensity of relation whereas human resource management as the least influential factor.

While organizations and policy makers have been working tirelessly to make supply chain networks disruption free but making it into reality takes quite an effort as it is influenced by multitude of factors. In such a scenario our study can act as a handbook for decision makers to identify and prioritize factors that can enable to frame a sustainable strategy against any sort of disruption-natural, geo-political, economic, or likewise. Our study can also be generalized across various sectors of the supply chain to overcome COVID like disruptions by building resilience.

\section{Appendix 1: AHP calculation process}

Step 1: Identification of critical factors and sub-factors and creating a hierarchal structure for developing a resilient supply chain.

Step 2: Making pairwise comparison between the identified factors using a nine-point scale (Saaty 2008) so as to form a pair wise comparison matrix using scales as listed below.

\section{Scales in pair-wise comparisons}

\begin{tabular}{ll}
\hline Importance intensity & Preference judgments \\
\hline 1 & Equally important \\
3 & Moderately important \\
5 & Strongly important \\
7 & Extremely important \\
9 & Extremely more important \\
$2,4,6,8$ & Intermediate values \\
& between adjacent scale \\
& values \\
\hline
\end{tabular}


Step 3: Determination of normalized weights for the identified factors and to form a normalized weight vector. Based upon the normalized vector, factors are ranked based on their weightage.

Step 4: Evaluating the consistency.

The maximum eigenvector $\left(\lambda_{\max }\right)$ is calculated which ensures consistency of achieved solution. Thereafter, Consistency Index (C.I.) is calculated using Eq. (1). Based on the C.I. and Random Consistency Index (R.I.), the Consistency Ratio (C.R.) is calculated using Eq. (2)

C.I. $=\frac{\lambda_{\max }-N}{N-1}$

The C.R. is then calculated using the formulae:

C.R. $=\frac{C I}{R I}$

where $N=$ Order of matrix.

The value to Random Consistency Index varies according to the order of matrix (Saaty 2008).

\section{Random consistency index}

\begin{tabular}{llllllllllll}
\hline $\begin{array}{l}\text { Order of } \\
\text { matrix }\end{array}$ & 1 & 2 & 3 & 4 & 5 & 6 & 7 & 8 & 9 & 10 & 11 \\
\hline RCI & 0 & 0 & 0.58 & 0.9 & 1.12 & 1.24 & 1.32 & 1.41 & 1.45 & 1.49 & 1.53 \\
\hline
\end{tabular}

To achieve better consistency in the comparative judgments and to ensure that decision-making is reliable in determining the ranking of critical factors, the calculated value of Consistency Ratio must be equal to or less than the acceptable Consistency Ratio.

\section{Appendix 2: DEMATEL calculation process}

- Step 1: Creation of direct relation average matrix (A) A pair wise comparison of the identified parameters is done by experts to determine the influence potential of one parameter over others. Each expert indicated their responses by using integers ( 0 to 5 ) in the matrixes which indicate that each parameter (i) can have five levels of influence over every other parameter (j).

1. Parameter $a_{i}$ does not influence $a_{j}=0$

2. Parameter $a_{i}$ has low influence over $a_{j}=1$

3. Parameter $\mathrm{a}_{\mathrm{i}}$ has medium influence over $\mathrm{a}_{\mathrm{j}}=2$

4. Parameter $\mathrm{a}_{\mathrm{i}}$ has high influence over $\mathrm{a}_{\mathrm{j}}=3$

5. Parameter $a_{i}$ has very high influence over $a_{j}=4$
Responses of the experts lead to formation of a non-negative matrix $(n * n)$.

After taking into account the responses of all the experts an average direct relation matrix (A) is obtained which is $\mathrm{a} \mathrm{n}^{*} \mathrm{n}$ matrix, where $\mathrm{n}$ is the number of identified parameters and $\mathrm{i}, \mathrm{j}$ indicates row and column respectively.

$A=\left[\begin{array}{ccccc}a_{11} & \ldots & a_{1 j} & \ldots & a_{1 n} \\ a_{21} & \ldots & a_{2 j} & \ldots & a_{2 n} \\ \ldots & \ldots & \ldots & \ldots & \ldots \\ a_{i 1} & \ldots & a_{i j} & \ldots & a_{i n} \\ \ldots & \ldots & \ldots & \ldots & \ldots \\ a_{n 1} & \ldots & a_{n j} & \ldots & a_{n n}\end{array}\right]$

- Step 2: Creation of normalized direct relation matrix $(\mathrm{Z})$

The direct relation matrix (A) as determined in step 1 is then multiplied by a factor $\mathrm{F}$ to get a $\mathrm{n} * \mathrm{n}$ normalized direct relation matrix $(\mathrm{Z})$. The factor $\mathrm{F}$ is determined using Eq. (3) and normalized direct relation matrix (Z) using Eq. (4)

$F=\min \left\{\frac{1}{\max i \sum_{j=1}^{n}\left|a_{i j}\right|}, \frac{1}{\max j \sum_{i=1}^{n}\left|a_{i j}\right|}\right\}$

$\mathrm{Z}=\mathrm{F}^{*} \mathrm{~A}$

Each element in the normalized direct relation matrix (Z) holds a value ranging from 0 to 1 with the major diagonal elements being 0 .

- Step 3: Calculation of total relation matrix (T)

Total relation matrix $(\mathrm{T})$ indicates total relationships between all pairs of identified parameters. The matrix $\mathrm{T}$ is calculated using Eq. (5) and element $\mathrm{t}_{\mathrm{ij}}$ of matrix $\mathrm{T}$ indicates indirect influence which parameter ' $\mathrm{i}$ ' has over parameter ' $\mathrm{j}$ '. The indirect influence continuously reduces along the powers of $\mathrm{T}$.

$$
\begin{aligned}
\mathrm{T}= & \mathrm{Z}+\mathrm{Z}^{2}+\mathrm{Z}^{3}+\ldots \mathrm{Z}^{\mathrm{h}}=\mathrm{Z}\left(1+\mathrm{Z}+\mathrm{Z}^{2}+\ldots \mathrm{Z}^{\mathrm{h}-1}\right) \\
& {\left[(\mathrm{I}-\mathrm{Z})(\mathrm{I}-\mathrm{Z})^{-1}\right]=\mathrm{Z}(\mathrm{I}-\mathrm{Z})^{-1}\left(\mathrm{I}-\mathrm{Z}^{\mathrm{h}}\right) }
\end{aligned}
$$

Thus when $\lim _{h \rightarrow \infty} Z^{h}=[0]_{n x n}$

$\mathrm{T}=\mathrm{Z}(\mathrm{I}-\mathrm{Z})^{-1}$

where $\mathrm{I}=$ is a $\mathrm{n} * \mathrm{n}$ identity matrix.

- Step 4: Determination of sums of rows and columns of Total Relation Matrix(T)

The sums of rows and columns of matrix $\mathrm{T}$ are determined as per Eqs. (6) and (7) and are represented by vectors $\mathrm{R}$ and $\mathrm{C}$ respectively.

$$
R=\left(R_{i}\right)_{n x 1}=\left[\sum_{j=1}^{n} t_{i j}\right]_{n x 1}
$$


$C=\left(C_{j}\right)_{1 x n}=\left[\sum_{i=1}^{n} t_{i j}\right]_{1 x n}$

$\mathrm{R}_{\mathrm{i}}$ is the sum of the $\mathrm{i}^{\text {th }}$ row and it indicates the direct and indirect effects of parameter ' $i$ ' over other parameters. $C_{j}$ is the sum of $\mathrm{j}^{\mathrm{th}}$ column and it indicates the direct and indirect influences of other parameters on parameter ' $\mathrm{j}$ '.

- Step 5: Calculation of threshold value $(\alpha)$

The aim purpose of calculating threshold value is to eliminate some minor effect elements from Total Relation Matrix (T) (Ou et al. 2008). Thus, elements in matrix T having a value lesser than threshold value is eliminated and the remaining elements are used for preparing the causal diagraph. Threshold value is the average of all the elements in matrix $\mathrm{T}$ and is determined as per Eq. (8)

$\alpha=\frac{\sum_{i=1}^{n} \sum_{j=1}^{n}\left[t_{i j}\right]}{N}$

where $\mathrm{N}$ is the total number of elements in the Total Relation Matrix (T).

Elements of Matrix $T\left(t_{i j}\right)$ having a value lesser than the threshold value $(\alpha)$ is eliminated so as to form the inner dependence matrix.

- Step 6: Development of causal diagram

The vectors $\mathrm{R}$ and $\mathrm{C}$ determined in step 4 is utilised for developing the causal diagram. The horizontal axis $(\mathrm{R}+\mathrm{C})$ indicates the importance of the identified parameters whereas the vertical axis $(\mathrm{R}-\mathrm{C})$ divides the parameters into cause and effect groups. If the value of $\mathrm{R}-\mathrm{C}$ is negative the parameter belongs to the effect group and is influenced by other parameters. On the other hand, if $\mathrm{R}-\mathrm{C}$ is positive it indicates a given parameter is a causal parameter and it significantly influences other parameters. Thus, the causal diagram gives an idea of- influential parameters and the relative importance of a given parameter over other parameters.

\section{Appendix 3: Evaluation and analysis of questionnaire}

\section{Phase 1: Validation of factors of questionnaire}

Greetings of the Day!

Dear respondent. The present research aims to evaluate the significance of risk resilient strategies to combat the impact of COVID-19 and develop a framework that ensures a sustainable supply chain management. We have identified the below mentioned critical factors through current literature. Please tick $(\sqrt{ })$ in the appropriate box (0 signifies irrelevance and 1 signifies relevance). Kindly add/delete/rephrase/merge the strategies, if required.

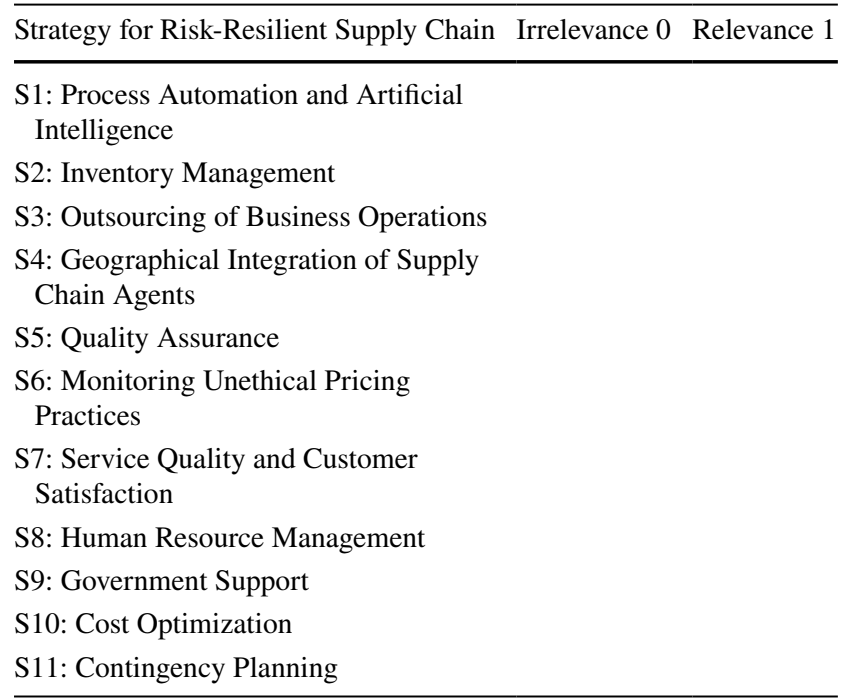

\section{Phase 2: Evaluating the factors}

Dear respondent. The present research further aims to analyse your response and evaluate the significance of risk resilient strategies to combat the impact of COVID-19 to develop a framework that ensures a sustainable supply chain management.

- Ranking among strategies using AHP

Please select and rank these strategies from the identified list of eleven crucial business strategies. Please select a strategy in the first column and in the first column and compare it with the rest on a scale of 1-9. Based on the guidelines provided below, please provide your responses in the matrix provided using a suitable rating scale.

e.g. If Inventory Management (S2) is chosen in first column and compared with Quality Assurance and (S4) and if you think S2 is moderately important over S4, then place ' 3 ' in $\mathrm{S}_{24}$ and 1/3 in $\mathrm{S}_{42}$.

\begin{tabular}{ll}
\hline Importance intensity & Preference judgments \\
\hline 1 & Equally important \\
3 & Moderately important \\
5 & Strongly important \\
7 & Extremely important \\
9 & Extremely more important \\
$2,4,6,8$ & Intermediate values \\
& between adjacent scale \\
& values \\
\hline
\end{tabular}




\begin{tabular}{|c|c|c|c|c|c|c|c|c|c|c|c|}
\hline \multicolumn{2}{|c|}{ Critical Factors } & S1 S2 & S3 & S4 & S5 & S6 & S7 & S8 & S9 & S10 & S11 \\
\hline $\begin{array}{l}\text { Process } \\
\text { Automa- } \\
\text { tion and } \\
\text { Artificial } \\
\text { Intelli- } \\
\text { gence }\end{array}$ & S1 & & & & & & & & & & \\
\hline $\begin{array}{l}\text { Inventory } \\
\text { Manage- } \\
\text { ment }\end{array}$ & S2 & & & & & & & & & & \\
\hline $\begin{array}{l}\text { Outsourc- } \\
\text { ing of } \\
\text { Business } \\
\text { Opera- } \\
\text { tions }\end{array}$ & S3 & & & & & & & & & & \\
\hline $\begin{array}{l}\text { Geographi- } \\
\text { cal Inte- } \\
\text { gration } \\
\text { of Supply } \\
\text { Chain } \\
\text { Agents }\end{array}$ & S4 & & & & & & & & & & \\
\hline $\begin{array}{l}\text { Quality } \\
\text { Assurance }\end{array}$ & S5 & & & & & & & & & & \\
\hline $\begin{array}{l}\text { Monitoring } \\
\text { Unethical } \\
\text { Pricing } \\
\text { Practices }\end{array}$ & S6 & & & & & & & & & & \\
\hline $\begin{array}{l}\text { Service } \\
\text { Qual- } \\
\text { ity and } \\
\text { Customer } \\
\text { Satisfac- } \\
\text { tion }\end{array}$ & S7 & & & & & & & & & & \\
\hline $\begin{array}{l}\text { Human } \\
\text { Resource } \\
\text { Manage- } \\
\text { ment }\end{array}$ & S8 & & & & & & & & & & \\
\hline $\begin{array}{l}\text { Government } \\
\text { Support }\end{array}$ & S9 & & & & & & & & & & \\
\hline $\begin{array}{r}\text { Cost Opti- } \\
\text { mization }\end{array}$ & $\mathrm{S} 10$ & & & & & & & & & & \\
\hline $\begin{array}{l}\text { Contingency } \\
\text { Planning }\end{array}$ & S11 & & & & & & & & & & \\
\hline
\end{tabular}

- Causal interrelationships among strategies using DEMATEL

Dear respondent. We also seek to determine the interrelationships among the stated risk resilient strategies to combat the impact of COVID-19. For this purpose, the following questionnaire is prepared to measure the interrelationship among these strategies on a $0-4$ scale. Based on the guidelines provided below, please provide your responses in the matrix provided using a suitable rating scale.

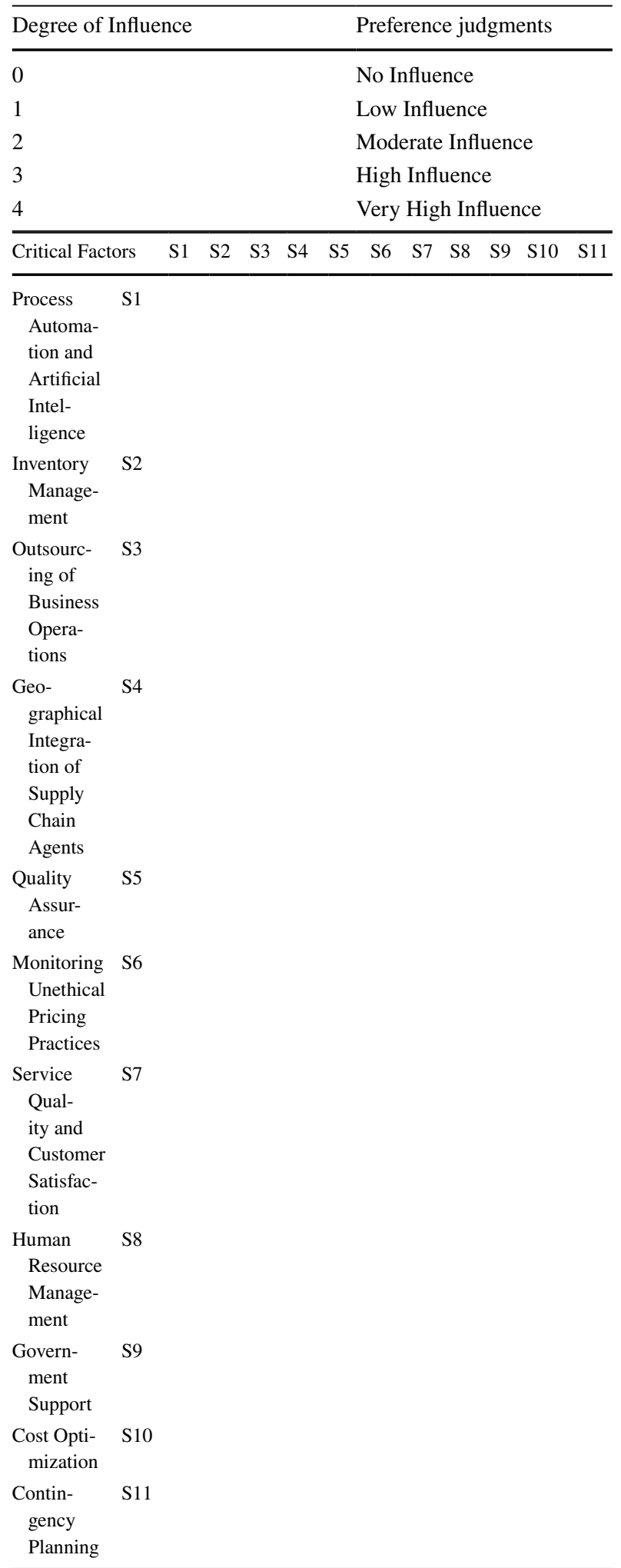

Funding No funding was received to assist with the preparation of this manuscript. 


\section{Declarations}

Conflicts of interest The authors have no relevant financial or nonfinancial interests to disclose.

\section{References}

Albayrak E, Erensal YC (2004) Using analytic hierarchy process (AHP) to improve human performance: An application of multiple criteria decision making problem. J Intell Manuf 15:491-503. https:// doi.org/10.1023/B:JIMS.0000034112.00652.4c

Barbieri P, Boffelli A, Elia S, Fratocchi L, Kalchschmidt M, Samson D (2020) What can we learn about reshoring after Covid-19? Oper Manag Res 13(3):131-136

Baryannis G, Validi S, Dani S, Antoniou G (2019) Supply chain risk management and artificial intelligence: state of the art and future research directions. Int J Prod Res 57(7):2179-2202

Belhadi A, Kamble S, Jabbour CJC, Gunasekaran A, Ndubisi NO, Venkatesh M (2021) Manufacturing and service supply chain resilience to the COVID-19 outbreak: Lessons learned from the automobile and airline industries. Technol Forecast Soc Chang 163:120447

Blackhurst J, Craighead CW, Elkins D, Handfield RB (2005) An empirically derived agenda of critical research issues for managing supply-chain disruptions. Int J Prod Res 43(19):4067-4081

Boffelli A, Fratocchi L, Kalchschmidt M (2021) Doing the right thing or doing things right: what is better for a successful manufacturing reshoring? Oper Manag Res 1-16

Cachon G, Fisher M (2000) Supply Chain Inventory Management and Value of Shared Information. Manage Sci 46:1032-1048. https:// doi.org/10.1287/mnsc.46.8.1032.12029

Cai X, Chen J, Xiao Y, Xu X, Yu G (2013) Fresh-product supply chain management with logistics outsourcing. Omega 41(4):752-765

Carter CR (2000) Ethical issues in international buyer-supplier relationships: a dyadic examination. J Oper Manag 18(2):191-208

Cheng EWL, Li H (2001) Analytic hierarchy process: an approach to determine measures for business performance. Meas Bus Excell 5(3):30-37

Chowdhury MMH, Quaddus MA (2015) A multiple objective optimization based QFD approach for efficient resilient strategies to mitigate supply chain vulnerabilities: The case of garment industry of Bangladesh. Omega 57:5-21

Chowdhury MT, Sarkar A, Paul SK, Moktadir MA (2020) A case study on strategies to deal with the impacts of COVID-19 Pandemic in the food and beverage industry. Oper Manag Res 1-13

Christopher M, Peck H (2004) Building the Resilient Supply Chain. The International Journal of Logistics Management 15(2):1-14. https://doi.org/10.1108/09574090410700275

Crook TR, Ketchen DJ, Combs JG, Todd SY (2008) Strategic resources and performance: a meta-analysis. Strateg Manag J 29(11):11411154. https://doi.org/10.1002/smj.703

Das D, Datta A, Kumar P (2020) Exit Strategies for COVID 19: An ISM and MICMAC approach. Asia Pacific Journal of Health Management 15(3):94-109. https://doi.org/10.24083/apjhm.v15i3.423

Day JM (2014) Fostering emergent resilience: the complex adaptive supply network of disaster relief. Int J Prod Res 52(7):1970-1988

Dube N, Van der Vaart T, Teunter RH, Van Wassenhove LN (2016) Host government impact on the logistics performance of international humanitarian organisations. J Oper Manag 47:44-57

El Baz J, Ruel S (2021) Can supply chain risk management practices mitigate the disruption impacts on supply chains' resilience and robustness? Evidence from an empirical survey in a COVID-19 outbreak era. Int J Prod Econ 233:107972
Farahani RZ, Elahipanah M (2008) A genetic algorithm to optimize the total cost and service level for just-in-time distribution in a supply chain. Int J Prod Econ 111(2):229-243

Fiksel J, Croxton KL, Pettit TJ (2015) From risk to resilience: learning to deal with disruption. MIT Sloan Manag Rev 56(2):78-86

Fontela E, Gabus A (1972) World Problems an Invitation to Further Thought within the Framework of DEMATEL. Battelle Geneva Research Centre, Geneva

Frazier GL, Spekman RE, O'Neal CR (1988) Just-in-time exchange relationships in industrial markets. J Mark 52(5):52-67

Golan MS, Jernegan LH, Linkov I (2020) Trends and applications of resilience analytics in supply chain modeling: systematic literature review in the context of the COVID-19 Pandemic. Environment Systems and Decisions 40:222-243

Goran S (2004) Key areas, causes and contingency planning of corporate vulnerability in supply chains: A qualitative approach. Int $\mathrm{J}$ Phys Distrib Logist Manag 34:728-748. https://doi.org/10.1108/ 09600030410567496

Guide VDR Jr, Jayaraman V, Linton JD (2003) Building contingency planning for closed-loop supply chains with product recovery. $\mathbf{J}$ Oper Manag 21(3):259-279

Gulledge T, Chavusholu T (2008) Automating the construction of supply chain key performance indicators. Ind Manag Data Syst 108:750-774. https://doi.org/10.1108/02635570810883996

Hale T, Moberg C (2005) Improving Supply Chain Disaster Preparedness: A Decision Process for Secure Site Location. Int J Phys Distrib Logist Manag 35:195-207. https://doi.org/10.1108/ 09600030510594576

Hoek, R. I. V. (1998). Reconfiguring the supply chain to implement postponed manufacturing. The International Journal of Logistics Management, 9(1), 95-110.

Hosseini S, Ivanov D, Dolgui A (2019) Review of quantitative methods for supply chain resilience analysis. Transp Res Part E 125:285-307

Infosys (2020) COVID-19 Supply Chain Impact Survey Snapshot: A Look at Readiness, Supplier Risk and Recovery. Retrieved from https://www.sdcexec.com/risk-compliance/press-release/21194137/ infosys-covid19-supply-chain-impact-survey-snapshot-a-look-atreadiness-supplier-risk-and-recovery

Institute for Supply Management (2020) COVID-19 Survey: Round 3 Supply Chain Disruptions Continue Globally. Retrieved from https:// www.prnewswire.com/news-releases/covid-19-survey-round-3-supplychain-disruptions-continue-globally-301096403.html

Ivanov D (2020) Predicting the Impact of Epidemic Outbreaks on the Global Supply Chains: A Simulation-Based Analysis on the Example of Coronavirus (COVID-19 / SARS-CoV-2) Case. Transp Res E 136:101922.https://doi.org/10.1016/j.tre.2020.101922

Ivanov D, Das A (2020) Coronavirus (COVID-19/SARS-CoV-2) and supply chain resilience: a research note. International Journal of Integrated Supply Management 13(1):90. https://doi.org/10.1504/ ijism.2020.107780

Ivanov, D, Dolgui A (2020) Viability of intertwined supply networks: extending the supply chain resilience angles towards survivability. A position paper motivated by COVID-19 outbreak. Int J Prod Res 58(10):2904-2915

Jabbour CJC, de Sousa Jabbour ABL (2016) Green human resource management and green supply chain management: Linking two emerging agendas. J Clean Prod 112:1824-1833

Johnson N, Elliott D, Drake P (2013) Exploring the role of social capital in facilitating supply chain resilience. Supply Chain Management: an International Journal 18(3):324-336

Karwasra K, Soni G, Mangla SK, Kazancoglu Y (2021) Assessing dairy supply chain vulnerability during the Covid-19 pandemic. Int J Log Res Appl 1-19

Keating B (2009) Managing ethics in the tourism supply chain: The case of Chinese travel to Australia. Int J Tour Res 11(4):403-408 
Kelle P, Akbulut A (2005) The role of ERP tools in supply chain information sharing, cooperation, and cost optimization. Int $\mathrm{J}$ Prod Econ 93:41-52

Kristianto Y, Helo P, Jiao JR, Sandhu M (2012) Adaptive fuzzy vendor managed inventory control for mitigating the Bullwhip effect in supply chains. Eur J Oper Res 216(2):346-355

Kroes JR, Ghosh S (2010) Outsourcing congruence with competitive priorities: Impact on supply chain and firm performance. J Oper Manag 28(2):124-143

Lee HL, So KC, Tang CS (2000) The value of information sharing in a two-level supply chain. Manage Sci 46(5):626-643

Legg S, Hutter M (2007) Universal intelligence: A definition of machine intelligence. Mind Mach 17(4):391-444

Lengnick-Hall ML, Lengnick-Hall CA, Rigsbee CM (2013) Strategic human resource management and supply chain orientation. Hum Resour Manag Rev 23(4):366-377

Linton T, Vakil B (2020) Coronavirus is proving that we need more resilient supply chains, Harvard Business Review Digital Article, available at: https://hbr.org/2020/03/coronavirus-isproving-thatwe-need-more-resilient-supply-chains\#comment-section

Mahmoudi A, Javed SA, Mardani A (2021) Gresilient supplier selection through Fuzzy Ordinal Priority Approach: decision-making in post-COVID era. Oper Manag Res 1-25

Mani D, Barua A, Whinston A (2010) An Empirical Analysis of the Impact of Information Capabilities Design on Business Process Outsourcing Performance. MIS Q 34:39-62. https://doi.org/10. 2307/20721414

Margolis JT, Sullivan KM, Mason SJ, Magagnotti M (2018) A multiobjective optimization model for designing resilient supply chain networks. Int J Prod Econ 204:174-185. https://doi.org/10.1016/j. ijpe.2018.06.008

Montgomery O (2020) 5 types of supply chain disruption With COVID19 Examples. Retrieved April 17, 2021, from https://www.softw areadvice.com/resources/supply-chain-disruption-types/

Pereira RC, Christopher M, Da Silva LA (2014) Achieving supply chain resilience: the role of procurement. Supply Chain Manag: Int J 19(5/6):626-642

Petersen KJ, Handfield RB, Ragatz GL (2005) Supplier integration into new product development: coordinating product, process and supply chain design. J Oper Manag 23(3-4):371-388

Politis Y, Giovanis A, Binioris S (2014) Logistics service quality and its effects on customer satisfaction in the manufacturing companies' supply chains. J Model Manag 9(2):215-237. https://doi.org/ 10.1108/jm2-05-2012-0016

Ponomarov SY, Holcomb MC (2009) Understanding the concept of supply chain resilience. Int J Logist Manag 20(1):124-143

Ragatz GL, Handfield RB, Petersen KJ (2002) Benefits associated with supplier integration into new product development under conditions of technology uncertainty. J Bus Res 55(5):389-400

Rajesh R (2017) Technological capabilities and supply chain resilience of firms: A relational analysis using Total Interpretive Structural Modeling (TISM). Technol Forecast Soc Chang 118:161-169

Remko VH (2020) Research opportunities for a more resilient postCOVID-19 supply chain - closing the gap between research findings and industry practice. Int J Oper Prod Manag 40(4):341355. https://doi.org/10.1108/IJOPM-03-2020-0165

Roberts P, Dowling G (2002) Corporate reputation and sustained superior financial performance. Strateg Manag J 23:1077-1093. https://doi.org/10.1002/smj.274

Rodrigue JP (2006) Transportation and the Geographical and Functional Integration of Global Production Networks. Growth Chang 37(4):510-525. https://doi.org/10.1111/j.1468-2257.2006.00338.x

Saaty RW (1987) The analytic hierarchy process-what it is and how it is used. Mathematical Modelling 9(3-5):161-176. https://doi. org/10.1016/0270-0255(87)90473-8
Saaty TL (2008) The Analytic Hierarchy and Analytic Network Measurement Processes: Applications to Decisions under Risk. Eur J Pure Appl Math 1(1)

Samson D (2020) Operations/supply chain management in a new world context. Oper Manag Res 13:1-3

Savitz AW, Weber K (2006) The Triple Bottom Line. Jossey-Bass, San Francisco, CA

Sawik T (2013a) Integrated selection of suppliers and scheduling of customer orders in the presence of supply chain disruption risks. Int J Prod Res 51(23-24):7006-7022

Sawik T (2013b) Selection and protection of suppliers in a supply chain with disruption risks. International Journal of Logistics Systems and Management 15:143-159. https://doi.org/10.1504/IJLSM. 2013.053763

Scholten K, Schilder S (2015) The role of collaboration in supply chain resilience. Supply Chain Management: an International Journal 20:471-484. https://doi.org/10.1108/SCM-11-2014-0386

Selko A (2021) Pandemic Reaction: What Supply Chains Did Right and Where They Can Improve. Retrieved April 17, 2021, from https://www.mhlnews.com/global-supply-chain/article/21160637/ pandemic-reaction-what-supply-chains-did-right-and-where-theycan-improve

Seth N, Deshmukh SG, Vrat P (2006) A framework for measurement of quality of service in supply chains. Supply Chain Management: an International Journal 11(1):82-94. https://doi.org/10. $1108 / 13598540610642501$

Seville E, Opstal VD, Vargo J (2015) A Primer in resiliency: seven principles for managing the unexpected. Glob Bus Organ Excell 34(3):6-18

Simangunsong E, Hendry LC, Stevenson M (2016) Managing supply chain uncertainty with emerging ethical issues. Int J Oper Prod Manag 36(10):1272-1307. https://doi.org/10.1108/ IJOPM-12-2014-0599

Sherman E (2020) 94\% of the Fortune 1000 are seeing coronavirus supply chain disruptions. Retrieved from https://fortune.com/ 2020/02/21/fortune-1000-coronavirus-china-supply-chain-impact/

Skipper J, Hanna J, Cegielski C (2009) Supply Chain Contingency Planning and Firm Adoption: An Initial Look at Differentiating the Innovators. Transp J 48(2):40-62

Soni U, Jain V (2011) Minimizing the vulnerabilities of supply chain: A new framework for enhancing the resilience. IEEE International Conference on Industrial Engineering and Engineering Management

Straight B (2020) IBM survey: COVID-19 has refocused executives on digitization and supply chain resiliency. Retrieved from https:// www.freightwaves.com/news/ibm-survey-covid-19-has-refoc used-executives-on-digitization-and-supply-chain-resiliency

Sureshchandar GS, Rajendran C, Anantharaman RN (2002) The relationship between service quality and customer satisfaction-a factor specific approach. J Serv Mark 16:363-379. https://doi.org/10.1108/ 08876040210433248

Talluri S, Narasimhan R (2004) A methodology for strategic sourcing. Eur J Oper Res 154(1):236

Thilmany D, Canales E, Low SA, Boys K (2021) Local Food Supply Chain Dynamics and Resilience during COVID-19. Appl Econ Perspect Policy 43(1):86-104

Vanpoucke E, Ellis S (2019) Building supply-side resilience - a behavioural view. Int J Oper Prod Manag 40(1):11-33

Varadaraj AJ (2020) Tackling Supply Chain Disruption During COVID19. Retrieved April 17, 2021, from www.industryweek. com/supply-chain/article/21132223/tackling-supply-chain-disru ption-during-covid19

Wen Z, Liao H (2021) Capturing attitudinal characteristics of decisionmakers in group decision making: application to select policy recommendations to enhance supply chain resilience under COVID19 outbreak. Oper Manag Res 1-16 
Wu L, Yue X, Jin A, Yen D (2016) Smart supply chain management: A review and implications for future research. The International Journal of Logistics Management 27:395-417. https://doi.org/10. 1108/IJLM-02-2014-0035

Yang OYP, Leu JD, Tzeng GH (2008) A novel hybrid MCDM model combined with DEMATEL and ANP with applications. Int J Operation Res 5(3): 160-168

Yadav S, Luthra S, Garg D (2020) Internet of things (IoT) based coordination system in Agri-food supply chain: development of an efficient framework using DEMATEL-ISM. Oper Manag Res 1-27
Yu W, Jacobs MA, Salisbury WD, Enns H (2013) The effects of supply chain integration on customer satisfaction and financial performance: An organizational learning perspective. Int J Prod Econ 146(1):346-358

Zsidisin GA, Ellram LM, Carter JR, Cavinato JL (2004) An analysis of supply risk assessment techniques. Int J Phys Distrib Logist Manag 34(5):397-413

Publisher's Note Springer Nature remains neutral with regard to jurisdictional claims in published maps and institutional affiliations. 